cooperation of existing magnetic observatories in Europe and other parts of the world.

As one of the principal desiderata is magnetic curves with very open time scale, it may not be out of place to explain that it is not necessary for this purpose to have a specially constructed magnetograph of the Eschenhagen or any similar pattern with small magnets. The ordinary Kew pattern magnetograph, with the usual damping arrangements, requires only a simple addition to the clock to work admirably as a rapid-motion instrument. Additions of this kind have been made to the Mauritius magnetograph by $\mathrm{Mr}$. Claxton, the Director of the Royal Alfred Observatory, and a similar arrangement has been made at Kew itself at a trifling cost. The jbjection has, indeed, been raised to the use of ordinary magnetographs for this purpose, that the natural period of vibration of the magnets may coincide with that of the short magnetic waves which it is especially desired to investigate. When Eschenhagen described his early observations he apparently believed that the earth mag netic waves were restricted to one or two definite short periods, notably one of about thirty seconds; and he approved a short period of vibration for the magnet system so as to avoid possible synchronism. The records at Potsdam and Bossekop, however, discussed by Prof Birkeland, and those taken elsewhere, show waves of al periods from eight or ten seconds up to several minutes, the longer-period waves being identical with those long familiar to all concerned with the records of the older types of magnetographs run at the ordinary slow rate. It would thus appear that synchronism is likely to happen very rarely, whatever type of magnetograph is employed. In some respects, of course, a very short period in the magnet system has its advantages, but it is not without its drawbacks. It means small magnets, entailing the use of small mirrors, and so necessitating a more intense light or more sensitive paper than is requisite when heavier magnet systems and larger mirrors are used. The greater robustness of the largemagnet systems is also a recommendation to those responsible for obtaining the records, especially at stations which do not possess a skilled mechanic and are not situated near large towns, a situation which the spread of electric tramways is fast rendering impossible.

C. CHREE.

\section{CORONATION HONOURS TO MEN OF SCIENCE.}

$A \mathrm{~S}$ we went to press last week, news of the King's A serious illness was published, and national rejoicing at the anticipated Coronation ceremonies was suddenly changed to sorrow and deep anxiety. Since then, the nation has been slowly recovering from the shock, and the favourable bulletins which the King's physicians have issued this week encourage the hope that the crisis has been successfully passed and that His Majesty's convalescence is assured.

The operation for perityphlitis, from which the King has been suffering, was decided upon by Lord Lister, Sir Thomas Smith, Sir Francis Laking, Sir Thomas Barlow and Sir Frederick Treves, who are in attendance upon the Sovereign. It is beyond our province to describe the medical history of the illness or the nature of the operation performed by Sir Frederick Treves; but we are glad to know that scientific knowledge renders it possible to give relief to the sufferer without the fear of complications which made the surgeon's work almost hopeless before the introduction of antiseptic methods. Remembering this, we trust that the dark days have been passed and that progress towards recovery will be uninterrupted.

When the illness of the King became known, it was scarcely expected that the honours to be conferred in NO. I705, vOL. 66$]$ connection with the Coronation would be announced. But by His Majesty's express wish the list was published on Thursday last, and we give below the names of men of science included in it. The new Order of Merit which has been created by the King is of particular interest. We have applied to the Lord Chamberlain for a copy of the Warrant of the Order, but so far have not received one ; the general principles upon which the Order is founded will, however, be gathered from the following information given to and by the Times:-

The new Order is clearly founded on the lines of the wellknown Prussian "Ordre pour le Mérite." It will have the same comprehensive range and character, including, besides British subjects who have won conspicuous distinction in the naval and military services, those who are exceptionally eminent as men of letters and in the fields of art and science. The number of its members will be, as is right, very restricted. It is, of course, primarily and essentially a British Order, but provision will be made for taking into its ranks distinguished foreign personages as honorary members. The badge of the Order, to be worn by its members, will consist of a cross of red and blue enamel of eight poinis, having the words "For Merit" (the motto of the Order) in gold letters within a laurel wreath on a blue enamel centre. The reverse of the badge will show the King's Royal and Imperial cipher in gold (two silver swords with gold hilts, placed saltirewise between the angles of the cross, being added in the case of members chosen for military or naval distinction) also within a laurel wreath, on a blue enamel centre; and the whole will be surmounted by the Imperial Crown enamelled in colour, and suspended by a parti-coloured ribbon of Garter blue and crimson, two inches broad. The Sovereign's insignia, except, of course, for the modifications necessary to distinguish the Royal dignity of the wearer, will be similar to the insignia worn by the ordinary members of the Order. The ceremony of the investiture will be from time to time conducted by the Sovereign as in the case of any other Order, the members designate being introduced by the officer of the Order in attendance. Members of the Order will be entitled to attach a facsimile of its badge and ribbon to their arms. The Seal of the Order will show a facsimile of the badge, impaled with the Royal Arms, on a white ground, with the legend "The Seal of the Order of Merit." June 26, as the day originally fixed for the Coronation ceremony, will be observed as the anniversary of the Order.

The Order only comprises one class of ordinary members, and of the twelve eminent men chosen as the first to be admitted, four are men whose names are familiar throughout the world of science.

Among the new Privy Councillors are Lord Kelvin and Lord Lister.

The new Baronets include Sir Andrew Noble, K.C.B., Sir Francis Laking and Sir Frederick Treves.

The honour of Knighthood has been conferred upon Dr. J. W. Collins, F.R.C.S., Mr. A. Cooper, F.R.C.S., Mr. H. Croom, president of the Royal College of Surgeons (Edinburgh); Dr. T. Fraser, F.R.S., president of the Royal College of Physicians of Edinburgh; $\mathrm{Mr}$. Victor Horsley, F.R.S., Mr. H. G. Howse, president of the Royal College of Surgeons ; Principal Oliver Lodge, F.R.S., Prof. W. Macewen, F.R.S., Principal Rücker, F.R.S., and Mr. J. Thornycroft, F.R.S.

In the Order of the Bath (Civil Division) Sir William Church, Bart., president of the Royal College of Physicians, and Prof. W. Ramsay, F.R.S., have been appointed Knight Commanders. Major Ronald Ross, F.R.S., and Prof. A. M. Worthington, F.R.S., have been appointed Companions of the same Order.

In the Military Division of the Order of the Bath, Admiral Sir Erasmus Ommanney, F.R.S., has been appointed Knight Commander.

The Kaisar-I-Hind medal for public service in India has been granted to Mr. Edgar Thurston, superintendent, Government Central Museum, Madras.

Finally, the new Order of Merit includes the names of four distinguished men of science, namely, Lord Rayleigh, Lord Kelvin, Lord Lister and Sir William Huggins. 